\title{
Group model building: a participatory approach to understanding and acting on
}

\section{systems}

\section{Christine Siokou $a, b, c$, Rebecca Morgana and Alan Shiella,b}

a The Centre of Excellence in Intervention and Prevention Science, Melbourne, Victoria, Australia

b The Australian Prevention Partnership Centre, Melbourne, Victoria, Australia

c Corresponding author: christinesiokou@ceips.org.au

\section{Article history}

Publication date: November 2014

Citation: Siokou C, Morgan R, Shiell A. Group model building: a participatory approach to understanding and acting on systems. Public Health Res Pract. 2014;25(1):e2511404. doi: http://dx.doi. org/10.17061/phrp2511404

\section{Key points}

- Group model building (GMB) is a means of engaging diverse stakeholders in a process for jointly understanding and addressing complex issues, such as disease prevention and health promotion

- Evaluations of GMB suggest the tool is useful for increasing engagement in systems practices, as well as increasing confidence in the use of systems ideas

- GMB is also an efficient process, despite the time required to engage in the group processes

\section{Abstract}

With mounting appreciation of the complexity of chronic disease, there is a growing need to understand the systemic causes of current health trends. This will support the development of a prevention system and the use of systems thinking to achieve better, more equitable and more sustainable health outcomes. With new language and a need to change our thinking, the push towards systems practice in preventive health is challenging, and calls for a method to support its application.

Group model building (GMB) is a participatory approach that is widely used to build the capacity of practitioners to think in a systems way. However, it is a resource-intensive approach that requires high-level buy-in and the investment of time. We discuss the evidence, including a systematic review of the literature examining the effectiveness of GMB approaches across a wide range of contexts. The results of the review are generally positive and suggest that GMB improves problem understanding, increases engagement in systems thinking, builds confidence in the use of systems ideas and develops consensus for action among diverse stakeholders. 


\section{Introduction}

Readers who are familiar with the Foresight obesity map will remember their impressions when first encountering the diagram (Figure 1). ${ }^{1}$ With 100 or so causal factors, and 300 or more connections linking each cause to one or more of the others, the Foresight diagram is a complicated, almost incomprehensible web of interconnectedness that depicts the drivers of obesity prevalence and the ways in which they depend on each other. The diagram is brilliantly useful in demonstrating the complexity of factors driving the current obesity trend, but the scale and number of interactions in the diagram make it difficult to see how one might use it in any practical way to develop systemic approaches to obesity prevention.

Growing appreciation of the complex nature of obesity prevention - and chronic disease prevention more generally - is driving calls for the increased use of systems theory and methods. This is especially evident in the creation of The Australian Prevention Partnership Centre, which is taking a systems approach to preventing chronic disease. The issues we face in public health often have multiple interconnected causes, and they involve multiple agencies and organisations with different agendas and sometimes different views on the nature of the problem to be addressed and the best way of intervening. Interconnections mean that partial solutions tried in one part of the system often have unanticipated consequences elsewhere.

The Foresight diagram encapsulates this systemic view of the world, but how are we to make sense of it all or do anything with it? Even if you were already enthused by the idea of systems, how do you avoid being daunted by the language, the unfamiliar concepts and the challenge of thinking about public health in so different and complex a manner? The Foresight diagram does not really help beyond giving a reason for the common feeling of being overwhelmed.

The secret is in recognising that the real power of the Foresight approach lies not in the causal loop diagram itself but in the process undertaken to get there (and beyond). In this paper, we describe one approach group model building (GMB) - which is used to ground systems theory in the experience of policy makers and practitioners. GMB does not provide all the answers, but it can be used to develop capacity to understand systems concepts, and to support systems practice. ${ }^{2}$

Figure 1. Obesity systems map

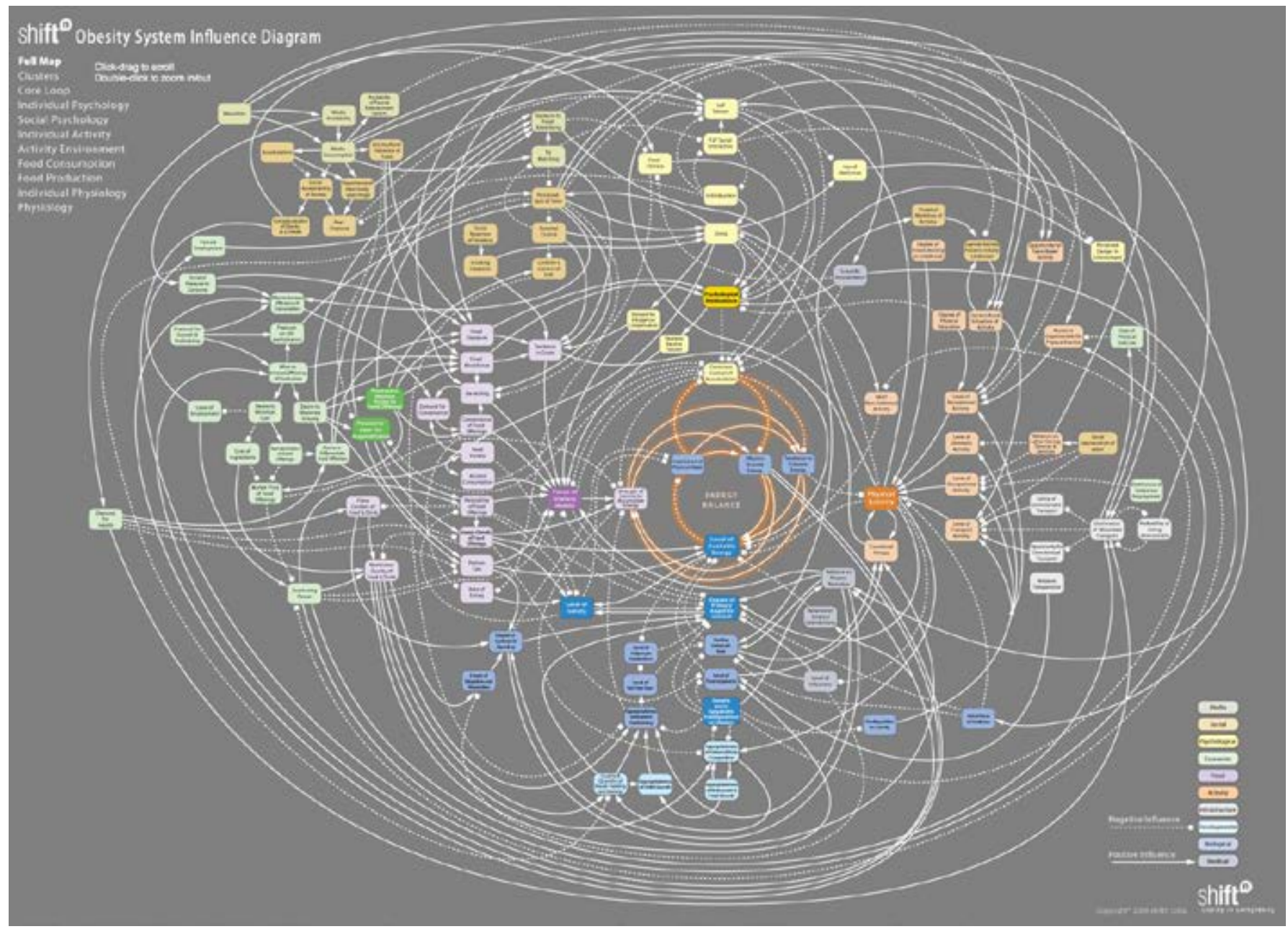

Source: Foresight - Tackling obesities: future choices. www.gov.uk/government/uploads/system/uploads/attachment_data/file/287937/07-1184xtackling-obesities-future-choices-report.pdf. To see a higher resolution, interactive version of this map go to www.shiftn.com/obesity/Full-Map.html 
Its participatory ethos is also consistent with the partnership approach that is a defining characteristic of The Australian Prevention Partnership Centre.

\section{What is group model building?}

GMB is just one of a number of ways of engaging stakeholders in the development of causal loop diagrams and other system dynamics models. ${ }^{2,3}$ Vennix ${ }^{2}$ defines GMB as "a process in which team members exchange their perceptions of a problem and explore questions such as: what exactly is the problem we face? How did the problematic situation originate? What might be its underlying causes? How can the problem be tackled?" It is a collaborative effort, potentially involving decision makers, technical experts, community members and so on, along with the modellers. A facilitated process is used, involving several scripted group exercises ${ }^{4}$ to develop a visual depiction of a problem of interest (e.g. the drivers of chronic disease) that can be used to guide policy and practice. ${ }^{5}$ The exercise can end with the construction of a causal loop map such as the Foresight diagram; however, this is usually just the first stage in a longer process spanning several months that eventually leads to identifying and evaluating systemic options for intervention, taking action on the problem, reflecting on the results, and then rethinking the problem in a new iteration.

The participatory process provides a practical means of introducing the core ideas of the systems approach to stakeholders and fosters a shared understanding of the problem to be addressed. Engagement of decision makers is also thought to engender a sense of confidence in using systems concepts and a common ownership of the solutions that emerge.

The literature shows that GMB is often used in the pursuit of improved understanding of the problem being investigated $^{6}$, and is tied to subsequent identification of more effective and readily implementable intervention strategies. ${ }^{7,8}$ Rouwette and colleagues ${ }^{9}$ have suggested that organisations that are introduced to systems modelling processes in GMB exercises are reliably able to continue using sophisticated modelling methods afterwards.

\section{How do you group-build a model?}

The content of any GMB exercise varies according to the demands of the problem and the preferences of the facilitator. However, common procedures can be seen in most efforts. ${ }^{10}$ These include:

1. Articulating the problem

2. Formulating dynamic hypotheses about how the system's behaviour is changing over time

3. Formulating a system dynamics model

4. Testing the model

5. Formulating potential strategies and evaluation.
Steps 1 and 2 tend to be qualitative, whereas steps 3-5 tend to be more quantitative. Step 3 marks the transition from a causal loop diagram, which is a qualitative descriptive of the causes of the problem being examined, to a stock and flow diagram, which allows simulation of the consequences of possible solutions. The systems field is currently divided on the merits of causal loop diagrams, some arguing that they are an intuitive introduction to systems thinking, and others arguing that they are a distraction that may be misleading. ${ }^{11}$

The facilitated group sessions involve both stakeholders and technical experts. A range of nominal group techniques is employed to uncover hidden assumptions, reveal differences in the language people are using, tabulate information and evidence on the dynamic nature of the problem being addressed, and more. All of this is aimed at creating a consensus view about which model of the system of interest can be constructed.

\section{Does group model building work?}

The promise of GMB is well understood, but is the potential fulfilled in practice? There is now a large number of reports of GMB exercises that provide some evidence. Rouwette and colleagues ${ }^{9}$ reviewed 107 cases of GMB where there was both some report of the process undertaken and some assessment of the results. There are problems with the dataset. For example, more than $80 \%$ of the papers included in the review described qualitative case studies that were largely based on observational data. Quantitative assessments tended to rely on post-test surveys, with only three studies employing a pre-test/post-test design. Statistical testing was therefore largely absent.

So, with the usual cautions in mind, what does the evidence show? The results are generally positive, although one needs to bear in mind that not every study reports on all dimensions of effect. Reactions to the exercises tend to be warm and supportive, with reports of improved organisational climate and team coherence. Insight is gained into the problem being addressed and the possible solutions. Consensus is also created in many studies, with commitment to take action. Studies report improvements in communications, although it is questionable whether the exercises help to develop a shared or common language. Finally, there is agreement that the GMB approach is an efficient means of addressing complex issues, despite the time required to participate in the exercises.

\section{Where next?}

At the Centre of Excellence in Intervention and Prevention Science, along with colleagues from Deakin University and financial support from the Johns Hopkins Global Center on Childhood Obesity, we are exploring whether 
a much less intensive but still hands-on workshop to introduce basic systems concepts can improve the confidence of health promotion practitioners in thinking about and using systems ideas. Early insights from that work are consistent with the review evidence. The Australian Prevention Partnership Centre is also considering whether the GMB approach might be used to facilitate engagement among policy makers, practitioners and researchers, and to support the development and implementation of effective systems-change interventions to tackle chronic disease.

\section{Competing interests}

Research reported in this publication was supported by the Global Obesity Prevention Center (GOPC) at Johns Hopkins of the National Institutes of Health under award number U54HD070725. The content is solely the responsibility of the authors and does not necessarily represent the official views of the National Institutes of Health.

\section{References}

1. Butland B, Jebb S, Kopelman P, et al. Tackling obesities: future choices - project report. 2nd ed. London: Foresight Programme of the Government Office for Science; 2007 [cited 2014 Oct 16]. Available from: www.gov.uk/ government/uploads/system/uploads/attachment_data/ file/287937/07-1184x-tackling-obesities-future-choicesreport.pdf
2. Vennix J. Group model building: facilitating team learning in system dynamics. Hoboken, NJ: John Wiley and Sons Ltd; 1996.

3. Andersen DF, Vennix JAM, Richardson GP, Rouwette EAJA. Group model building: problem structuring, policy simulation and decision support. Undated [cited 2014 Sep 21]. Available from www.albany.edu/ gpr/JORS06.pdf

4. Hovmand PS, Andersen DF, Rouwette E, Richardson GP, Rux K, Calhoun A. Group model building "scripts" as a collaborative tool. Syst Res Behav Sci. 2012;29:179-93.

5. Andersen DF, Richardson GP. Scripts for group model building. Syst Dyn Rev. 1997;13:107-29.

6. Doyle JK, Ford DN. Mental models concepts for system dynamics research. Syst Dyn Rev. 1998;14(1):3-29.

7. Fowler A. Systems modelling, simulation, and the dynamics of strategy. J Bus Res. 2003;56(2):135.

8. Hunt J, Timoshkina Y, Baudains P, Bishop S. System dynamics applied to operations and policy decisions. Eur Rev. 2012;20(3):324-42.

9. Rouwette EAJA, Vennix JAM, van Mullekom T. Group model building effectiveness: a review of assessment studies. Sys Dyn Rev. 2002;18(1):5-45.

10. Berard C. Group model building using system dynamics: an analysis of methodological frameworks. EJBRM 2010;8(1):35-46.

11. Richardson GP. Problems with causal loop diagrams. Syst Dyn Rev 1986;2:158-70.

\section{Copyright: (c) () (2)}

(C) 2014 Siokou et al. This article is licensed under the Creative Commons Attribution-NonCommercial-ShareAlike 4.0 International License, which allows others to redistribute, adapt and share this work non-commercially provided they attribute the work and any adapted version of it is distributed under the same Creative Commons licence terms. See: http://creativecommons.org/licenses/by-nc-sa/4.0/ 